March 2003

\title{
Equilibria with Local Governments and Commuting: Income Sorting vs. Income Mixing
}

Charles A. M. de Bartolome

University of Colorado

Stephen L. Ross

University of Connecticut

Follow this and additional works at: https://opencommons.uconn.edu/econ_wpapers

\section{Recommended Citation}

de Bartolome, Charles A. M. and Ross, Stephen L., "Equilibria with Local Governments and Commuting: Income Sorting vs. Income Mixing" (2003). Economics Working Papers. 200201.

https://opencommons.uconn.edu/econ_wpapers/200201 


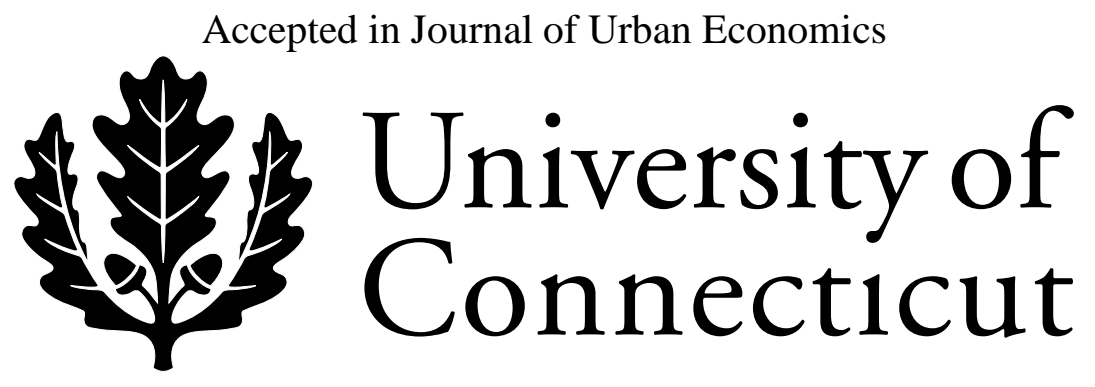

Department of Economics Working Paper Series

Equilibria with Local Governments and Commuting: Income Sorting vs. Income Mixing

Charles A. M. de Bartolome

University of Colorado

Stephen L. Ross

University of Connecticut

Working Paper 2002-01R

June 2002 (revised March 2003)

341 Mansfield Road, Unit 1063

Storrs, CT 06269-1063

Phone: (860) 486-3022

Fax: (860) 486-4463

http://www.econ.uconn.edu/ 


\begin{abstract}
Tiebout's (1956) model of fiscal competition suggests income sorting between jurisdictions while the Alonso (1964), Mills (167) and Muth (1969) model of the monocentric city suggests income sorting over space. However, strict income sorting is not empirically observed. We add fiscal competition to the spatial model by considering a circular inner city surrounded by a suburb. The fiscal difference between the jurisdictions and the commuting advantage of locations closer to the city center are capitalized into house prices. In addition to the traditional equilibrium with income sorting, there are equilibria with income mixing - both across jurisdictions and across space.
\end{abstract}

Journal of Economic Literature Classification: H73, R12, R14

Keywords: Community, sorting, capitalization 


\section{INTRODUCTION}

An important issue in local public economics is whether a household's mobility within a metropolitan area leads to jurisdictions in which residents have similar incomes. In Tiebout's [24] model of fiscal competition, jurisdictions are formed on a featureless plain and jurisdictional boundaries may be freely adjusted. Each jurisdiction provides a public service which is financed by a head-tax. A household's income does not depend on the jurisdiction in which it resides. A household shops over jurisdictions, choosing the jurisdiction which provides his preferred public service level. If the public service is a normal good, households with different incomes demand different public service levels. In consequence, households with different incomes chose different jurisdictions, or all households within each jurisdiction have the same income (McGuire [13], Berglas [2] and Wooders [27]). The prediction of households sorting themselves by income between jurisdictions is robust if the model is changed to have a finite number of jurisdictions with fixed boundaries: incomes in each jurisdiction lie in an interval, and the lowest income in one jurisdiction is the highest income in another jurisdiction (Elickson [7], Yinger [28], Epple, Filimon and Romer [9]). ${ }^{1}$ We term this outcome "income sorting between jurisdictions".

An alternative model of the income distribution within a metropolitan area is Alonso [1], Mills [15] and Muth's [17] model of the "monocentric city" with its emphasis on spatial sorting. The metropolitan area has, at its center, a central business district to which each household commutes. The advantage of a location closer to the metropolitan center is capitalized in its land price, so that land prices rise as locations move closer to the metropolitan center. If land demand is unresponsive to income changes and commuting costs increase with income, rich households 
outbid poor households for locations closer to the city's center. Conversely, if land demand is sufficiently income elastic, the saving achieved by the purchase of land further from the city's center is greater for the rich households and compensates them for the associated increase in commuting cost. In this case rich households choose to live in the low-priced locations further from the city's center. In both cases the prediction is of a monotonic relationship between household income and distance from the metropolitan center (Wheaton [26]). ${ }^{2}$ We term this outcome "income sorting over space".

Unfortunately, the data do not support income sorting either between jurisdictions or across space. In contradiction to income sorting between jurisdictions: A significant percentage of families in both the inner city and in the suburbs have income below the poverty level (14.1\% and 6\% respectively in 1989); ${ }^{3}$ Pack and Pack $[19,20]$ find larger income variation within the towns of the metropolitan areas of Pennsylvania than is consistent with the homogeneous jurisdictions predicted by the Tiebout model; Persky [21] examines Chicago and finds considerable evidence of income heterogeneity in both the city and the suburbs; Epple and Platt [8] consider the Boston metropolitan area and find that the incomes of the wealthiest households in a jurisdiction of low average income exceed the incomes of the poorest households in a jurisdiction of high average income. In contradiction to income sorting across space: Glaeser, Kahn and Rappaport [11] find that, for "old" cities, as the location moves out from the metropolitan center, household income falls, then rises at the boundary between the inner city and the suburbs, and then falls again.

In order to evaluate the many federal and state programs which provide aid to inner cities, it would seem important to create a model which predicts the empirically relevant 
outcome of income mixing. In this spirit, various modifications have been made to Tiebout's model. Berglas [3], Stiglitz [23], McGuire [14] and Brueckner [5] require that a household must work at a firm located in the same jurisdiction as he resides; income mixing arises because firms have a production technology which requires the use of low- and high-skilled workers. Berglas and Pines [4] suggest that jurisdictions provide several different public services. If the optimal jurisdiction size for one public service is less than for another, it may be desirable to add to the jurisdiction households who are relatively large users of the second public service. Nechyba [18] allows jurisdictions to have a mixed (and fixed) housing stock: the large houses in the poor jurisdiction are chosen by some rich households. Epple and Platt [8] create income mixing by allowing households to differ both in their incomes and in their preferences for the public service.

In this paper we show that a model which combines elements of the models of fiscal competition and of the monocentric city can predict income mixing between jurisdictions and across space. Specifically, we consider a metropolitan area to be comprised of a circular inner city surrounded by a suburb. All households commute to a central business district at the center of the inner city. A household's cost of commuting is proportional to the distance traveled and to its income, and land demand is income inelastic. We consider households to belong to one of two income classes - "poor" and "rich" households. These assumptions simplify the analysis by ensuring that within each jurisdiction rich households live closer to the metropolitan center. There is always one equilibrium in which there is a monotonic relationship between income and distance from the metropolitan center: this equilibrium corresponds to the case of income sorting between jurisdictions and across space, and may be associated with undeveloped land in the 
inner city. In addition to the equilibrium with income sorting, there can be a second equilibrium in which there is income mixing across space or, in the most interesting case, income mixing between jurisdictions and across space.

In the equilibrium with income mixing between jurisdictions and across space, poor households form the majority in the inner city and vote a low public service level; in the suburb rich households form the majority and vote a high public service level. Capitalization underlies the equilibrium. Because the cost of commuting increases with income, land prices can adjust to make both the rich households and the poor households indifferent between jurisdictions. For the rich households, land prices plus commuting costs are higher in the suburb than in the inner city, and the higher price offsets the benefit of the higher suburban public service. For the poor households, land prices plus commuting costs are lower in the suburb, and the lower price compensates for the disadvantage of the higher public service.

Our model has similarities to the model of LeRoy and Sonstelie [12]. LeRoy and Sonstelie consider how the cost of transportation effects the location of households in a metropolitan area. They have two income classes with different commuting costs, and two modes of transport which are labeled "automobile" and "bus". Automobile travel is faster but more expensive, and in consequence households living closer to the metropolitan center commute on the bus but households living further out buy and use automobiles. Land demand is income inelastic so that ceteris paribus rich households outbid poor households for locations closer to the city center. This gives rise to "income mixing over space" similar to the income mixing over space in our model. In the inner circle around the metropolitan center, households commute by bus and rich households live on the inside and poor households live on the outside. 
Around this inner circle is a ring in which residents buy and use cars to commute. Although the final income gradient in LeRoy and Sonstelie is descriptively similar to our income gradient, there are important differences. In LeRoy and Sonstelie, there are no jurisdictions and hence no role for fiscal differences. In turn, this implies that house prices are continuous in the metropolitan area whereas in our model house prices change discontinuously as the location moves across the jurisdictional boundary between the inner city and the suburb.

The paper is organized as follows. In Section 2 lays out the general model. Section 3 presents the traditional equilibrium of income sorting. Section 4 presents the equilibrium with income mixing. Section 5 concludes. 


\section{THE MODEL}

A household obtains utility from consuming a private good $c$ and from a public service $g_{j}$ provided by the jurisdiction $j$ in which he lives: his utility is written $U\left(c, g_{j}\right)$. Each household inhabits a fixed space $a$. We assume that the lot size $a$ is fixed because this assumption ensures the existence of an equilibrium with income sorting, which is our base case. ${ }^{4}$ The non-land components of housing are included as part of the private good; therefore housing per se does not enter the utility function.

The private good is the numeraire good. The resource cost of one unit of the public service per household is one unit of numeraire. It is well-known in the literature that the use of a property tax to finance local public spending provides an incentive for low-income households to move into high-income jurisdictions (e.g. Wheaton [25]). The focus of this paper is to show that income mixing between jurisdictions is possible without this incentive, and we therefore assume that jurisdiction $j$ finances its public service with a residency tax $g_{j}$.

The jurisdiction is located in a metropolitan area. Each household must commute to the center of the metropolitan area to work. He has a unit time endowment which he can use for either working or commuting. If he lives at the metropolitan center and thereby spends no time commuting, his income endowment is $M$. If he lives a distance $d$ from the metropolitan center, his income is reduced because of his commuting time. His commuting time is proportional to the distance traveled and the opportunity cost of a unit of his time is $M$; therefore his cost of commuting is $t M d$. The price of land at $d$ is $r(d)$. The central government may provide a lumpsum transfer $T$. The household's problem is to choose the jurisdiction and his location in that jurisdiction: 


$$
\max _{j, d} U\left(c, g_{j}\right) \text { subject to } c=M-t M d-\operatorname{ar}(d)-g_{j}+T \text {. }
$$

There are two income classes: poor households have income $M_{1}$ and rich households have income $M_{2}: M_{1}<M_{2}$. The commuting benefit of locating closer to the metropolitan center is greater for rich households or, within a jurisdiction, rich households outbid the poor households for the locations closer to the metropolitan center. In consequence, rich households live on the inside and poor households on the outside of each jurisdiction. This is formalized in Lemma A. ${ }^{5}$

LEMMA A: Within a jurisdiction, household income is a weakly decreasing function of distance from the metropolitan center.

PROOF: Lemma A is shown by establishing that the slope of the bid-rent function of a rich household is steeper than the bid-rent function of a poor household.

At equilibrium, a household of income $M_{i}$ achieves utility $\bar{V}\left(M_{i}\right)$. Denote the bid of a household of income $M_{i}$ for a location in jurisdiction $j$ at radius $d$ from the metropolitan center as $r_{i j}(d):$

$$
U\left(M_{i}-t M_{i} d-a r_{i j}(d)-g_{j}+T, g_{j}\right)=\bar{V}\left(M_{i}\right)
$$

Hence within the jurisdiction $j$ :

$$
t M_{i} d+a r_{i j}(d)=\text { constant }
$$


Differentiate to find the slope of the bid-rent curve within the jurisdiction:

$$
\frac{d r_{i j}(d)}{d d}=-\frac{t M_{i}}{a}
$$

$M_{1}<M_{2}$ implies

$$
\frac{d r_{2 j}(d)}{d d}<\frac{d r_{1 j}(d)}{d d}<0 . \#
$$

The total number of households is denoted $N$, of which a fraction $\theta$ are poor. All households of income $M_{i}$, who live in jurisdiction $j$ at distances $d$ from the metropolitan center, achieve the same utility $U\left(M-t M_{i} d-a r(d)-g_{j}+T, g_{j}\right)$ or, for the distances $d$ at which they live

$$
t M_{i} d+a r(d)=\text { constant } .
$$

It is convenient to denote this constant by $b_{i j}$ :

$$
b_{i j} \equiv t M_{i} d+a r(d),
$$

and, in the subsequent analysis, to represent the rent paid by a household of income $M_{i}$ in jurisdiction $j$ as $\operatorname{ar}(d)=b_{i j}-t M_{i} d$. 


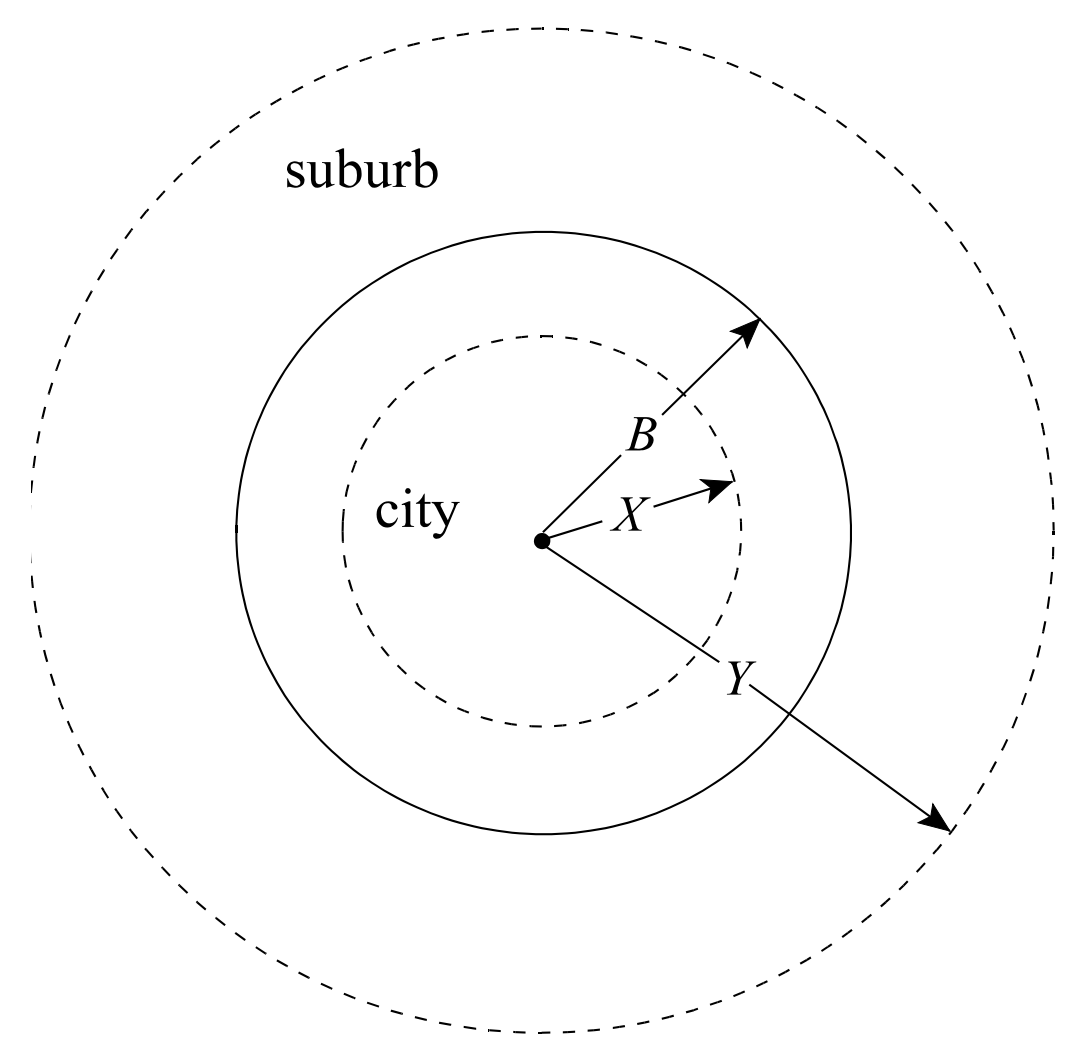

Figure 1: the metropolitan area

Figure 1 shows the metropolitan area. At the center of the metropolitan area is the business district to which all households must commute ${ }^{6}$; it is assumed to be a point with no area. The business district is surrounded by a circular jurisdiction, termed the "city" and labelled $c$; the city has an exogenous jurisdictional boundary of radius $B$. The outer edge of development in the city is $X$, which may equal $B$ in equilibrium. The city is surrounded by another jurisdiction, termed the "suburb" and labelled $s$. The limit of development in the suburb is distance $Y$ from the metropolitan center. We assume that the city's area cannot accommodate all households and the our focus is on how the two income groups distribute themselves between the two jurisdictions. 
The equilibrium conditions are now described. We illustrate each qualitative condition with the associated equation for the specific configuration in which all the rich households live in the city, form the majority in the city but do not fill the city, in which poor households live in the city and in the suburb, and in which there is no undeveloped land $(X=B)$. The boundary between the rich and poor households in the city has radius $x$. The equations for other configurations are presented in Appendices A and B.

1. Reservation land price: the reservation price of land is $r_{0}$ (for an area $a$ of land). For our illustrative case, poor households live at the edge of suburban development or, using Equation (1) to infer rent,

$$
b_{1 s}-t M_{1} Y=r_{0}
$$

For the illustrative case, there is no undeveloped land in the city so that the rent at the inside of the jurisdictional boundary must equal or exceed $r_{0}$. Using Lemma A, it is poor households who live at the inside of the jurisdictional boundary, so that the rent there is $\mathrm{b}_{1 c}-t M_{1} B$ and hence

$$
b_{1 c}-t M_{1} B \geq r_{0}
$$

2. Rent continuity: the rent is continuous in a jurisdiction. If it were discontinuous, a household living on the side of high rent could increase his utility by moving across the discontinuity: his rent would decrease discretely but his commuting cost would change only marginally. At distance $x$ from the metropolitan center, Equation (1) and rent continuity implies 


$$
b_{2 c}-t M_{2} x=b_{1 c}-t M_{1} x .
$$

3. No migration. If households of given income live in both jurisdictions, they must achieve the same utility in both jurisdictions. Alternatively, if households of given income live in only one jurisdiction, they must achieve at least as much utility in that jurisdiction as they could achieve by moving. For the illustrative case, poor households live in both jurisdictions and hence they achieve the same utility in both jurisdictions:

$$
U\left(M_{1}-b_{1 c}-g_{c}+T, g_{c}\right)=U\left(M_{1}-b_{1 s}-g_{s}+T, g_{s}\right)
$$

Continuing with the illustrative case, rich households live only in the city. If a rich household were to move to the suburb, he would achieve most utility by locating at the inner boundary where the rent is $b_{1 s}-t M_{1} B$, so

$$
U\left(M_{2}-b_{2 c}-g_{c}+T, g_{c}\right) \geq U\left(M_{2}-t M_{2} B-\left(b_{1 s}-t M_{1} B\right)-g_{s}+T, g_{s}\right) \text {. }
$$

4. Determination of the public service. The public service level is determined by majority voting. We assume that households vote myopically, taking the rent paid as given.

Hence the equilibrium public service level is the level desired by the income group which forms the majority in the jurisdiction. ${ }^{7}$ For the illustrative case, rich households form the majority in the city, or

$$
g_{c}=\underset{g}{\operatorname{argmax}} U\left(M_{2}-b_{2 c}-g+T, g\right)
$$


and poor households form the majority in the suburb, or

$$
g_{s}=\underset{g}{\operatorname{argmax}} U\left(M_{1}-b_{1 s}-g+T, g\right)
$$

5. Land equilibrium: the land available to each income class must equal the land consumed by each income class. For the illustrative case: ${ }^{8}$

$$
\begin{aligned}
& \pi x^{2}=(1-\theta) N a \\
& \pi Y^{2}=N a .
\end{aligned}
$$

6. Model closure. We assume that all rent is collected and returned to households as the lump-sum transfer $T$. For the illustatrative case, using Equation (1) to infer rents:

$$
T=\frac{1}{N}\left[\int_{0}^{x} \frac{b_{2 c}-t M_{2} d}{a} 2 \pi d d d+\int_{x}^{B} \frac{b_{1 c}-t M_{1} d}{a} 2 \pi d d d+\int_{B}^{Y} \frac{b_{1 s}-t M_{1} d}{a} 2 \pi d d d\right]
$$

7. The population in each jurisdiction is considered to be a continuous variable.

Our analysis focuses on the sorting of households between jurisdictions and across space. In general, income sorting (mixing) between jurisdictions arises when the income intervals of the different jurisdictions do not (do) overlap. Income sorting (mixing) across space arises when there is (is not) a monotonic relationship between income and distance from the metropolitan center. In our model with the income distribution massed at two income levels, with two jurisdictions and with the rich living on the inside of a jurisdiction, the classification is simplified. Income sorting between jurisdictions occurs when at least one jurisdiction contains 
only one income class; the other jurisdiction may contain both income classes. In contrast, income mixing between jurisdictions occurs if both jurisdictions contain both income classes. Income sorting across space occurs if income decreases weakly monotonically with distance from the metropolitan center; alternatively there is income sorting across space if all poor households live in the city and all rich households live in the suburb. Income mixing across space occurs if such a monotonic relationship does not exist. These relationships are illustrated in Figure 2. If there is income mixing across jurisdictions, there cannot be income sorting across space, or the bottom left cell of Figure 2 is empty.

\begin{tabular}{|c|c|c|c|}
\hline & \multicolumn{2}{|l|}{ across space } \\
\hline & & $\begin{array}{l}\text { sorting: monotonic } \\
\text { relationship between } \\
\text { income and distance }\end{array}$ & $\begin{array}{l}\text { mixing: non- } \\
\text { monotonic } \\
\text { relationship between } \\
\text { income and distance }\end{array}$ \\
\hline \multirow{2}{*}{$\begin{array}{l}\text { across } \\
\text { jurisdictions }\end{array}$} & $\begin{array}{l}\text { sorting: at least one } \\
\text { jurisdiction contains } \\
\text { only one income } \\
\text { group. }\end{array}$ & $\begin{array}{l}\text { all rich reside inside } \\
\text { of poor or both } \\
\text { jurisdictions are } \\
\text { homogeneous in } \\
\text { income. }\end{array}$ & $\begin{array}{l}\text { some rich reside } \\
\text { outside of poor but } \\
\text { both jurisdictions } \\
\text { are not homogenous } \\
\text { in income }\end{array}$ \\
\hline & $\begin{array}{l}\text { mixing: both } \\
\text { jurisdictions contain } \\
\text { both income groups }\end{array}$ & this cell is empty & $\begin{array}{l}\text { both classes reside } \\
\text { in each jurisdiction }\end{array}$ \\
\hline
\end{tabular}

Figure 2: sorting classification 


\section{EQUILIBRIUM WITH INCOME SORTING}

This section examines the equilibrium configuration with the strongest form of income sorting - income sorting between jurisdictions and across space (i.e., the upper left cell of Figure 2). In order to establish the existence of such an equilibrium, we need to assume certain properties for the utility function,

ASSUMPTION : $U(\cdot ;)$ is a strictly concave function in both of its arguments, and $g$ is a normal good. In addition, $\operatorname{Lim}_{\mathrm{c} \rightarrow 0} U(c,),. \underset{g \rightarrow 0}{\operatorname{Lim}} U(., g)<U(c, g) \forall c>0, g>0$.

In addition we assume that poor households have sufficient income to live in the suburb. ${ }^{9}$ With these restrictions, Theorem 1 shows that at any value of $N, \theta$ or $B$, there exists an equilibrium with income sorting between jurisdictions and across space.

THEOREM 1: an equilibrium with income sorting between jurisdictions and across space exists.

PROOF: the proof is available from the authors on request.

As an example of a sorting equilibrium, consider the case used in Section 2 to illustrate the equilibrium conditions. Rich households live in the city and form the majority in the city, poor households live in the city and in the suburb, and there is no undeveloped land in the city. An equilibrium of this form requires that values of the eight variables $b_{2 c}, b_{1 c}, b_{1 s}, g_{c}, g_{s}, x, Y$ and $T$ can be found which solve Equations (2), (4), (5), (7)-(11) and which satisfy Inequalities (3) and (6) ${ }^{10}$. The rent schedule for this equilibrium is shown in Figure 3(a) below. ${ }^{11}$ 


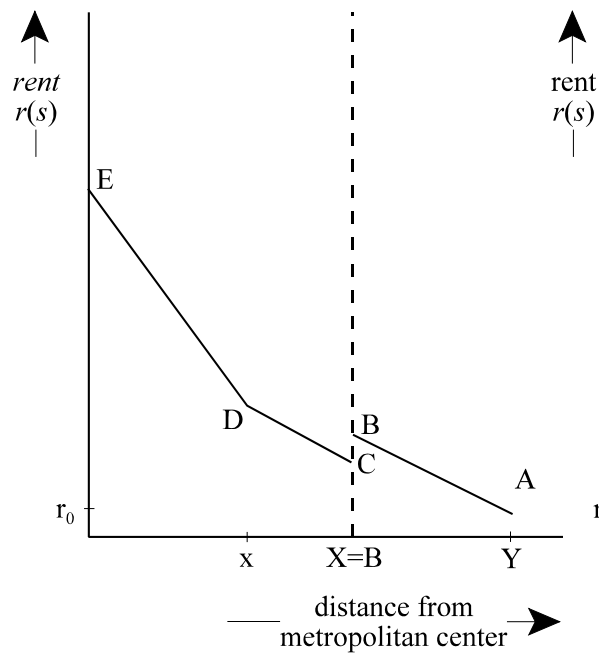

(a)

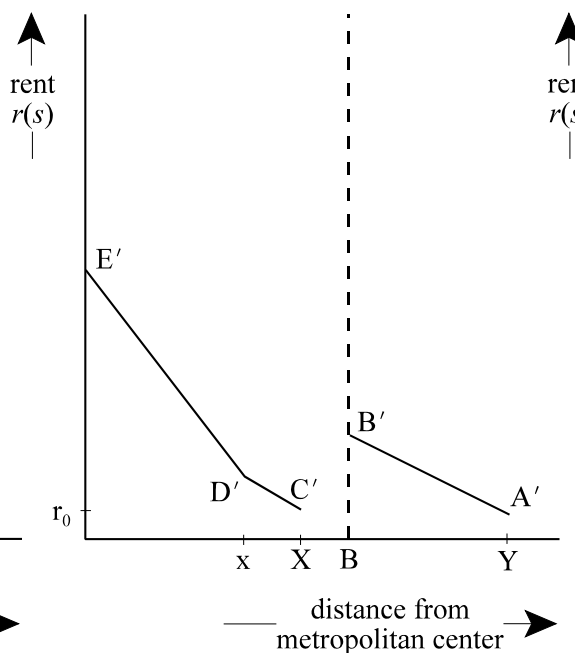

(b)

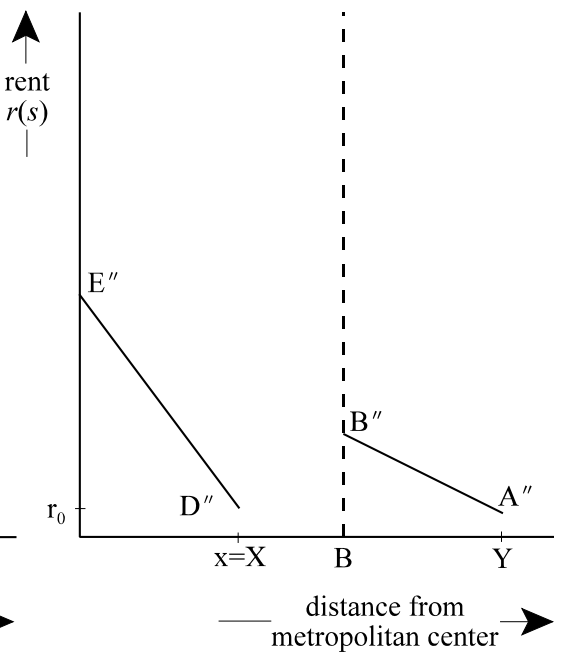

(c)

Figure 3: possible rent schedules with income sorting.

In Figure 3(a), there is no undeveloped land: $X=B$. Poor households live at the suburban fringe where the rent is anchored at $r_{0}$. As the residential location moves inwards, the rent schedule is $A B$ : the commuting advantage to the poor household is capitalized so that the rent rises at rate $t M_{1}$. As the location moves across the city's boundary, the public service level changes from the level chosen by poor households to the level chosen by rich households. The fall in rent $B C$ represents the cost to the poor household of the city's higher public service (and associated taxes). Poor households live in the outside of the city and, as the location continues to move inwards, the rent schedule is $C D$ with slope $t M_{1}$. However, at distance $x$ from the metropolitan center, households become rich and the rent schedule's slope along $D E$ steepens to $t M_{2}$, reflecting the advantage to a rich household of a marginally smaller commute.

The reservation rent $r_{0}$ is a rent floor. In Figures 3(b) and 3(c), the poor have a sufficiently low willingness to pay for the higher public service in the city that they are unwilling 
to pay rent $r_{0}$ to live at the city side of the boundary $B$. As the location moves closer to the metropolitan center, the benefit of the shorter commute increases and, in Figure 3(b), the location becomes attractive to poor households at distance $X$ from the metropolitan center. Hence there is undeveloped city land: $X<B$. In Figure 3(c), even at distance $x$ a poor household is unwilling to pay rent $r_{0}$ and the city contains no poor households: $x=X$. Theorem 1 tells us that, with the number of rich households being sufficient to fill at least half the city's area but not all the city's area, at least one of the configurations shown in Figure 3 is an equilibrium.

To illustrate the potential importance of undeveloped land, we solve the problem in which households have utility functions of Cobb-Douglas form:

$$
(1-\alpha) \log _{e} c+\alpha \log _{e} g
$$

We consider particular parameter values $M_{1}=.3, M_{2}=.6, \theta=.6, B=7, N a=\pi\left(10^{2}\right)$ and $r_{0}=0$, and vary $\alpha$ and $t$. Figure 4 shows the three regions (a) no undeveloped city land, $x<X=B$; (b) undeveloped city land and poor households live in the city, $x<X<B$; and (c) undeveloped city land and no poor households live in the city, $x=X<B$. The last two regions with undeveloped city land are shaded. 


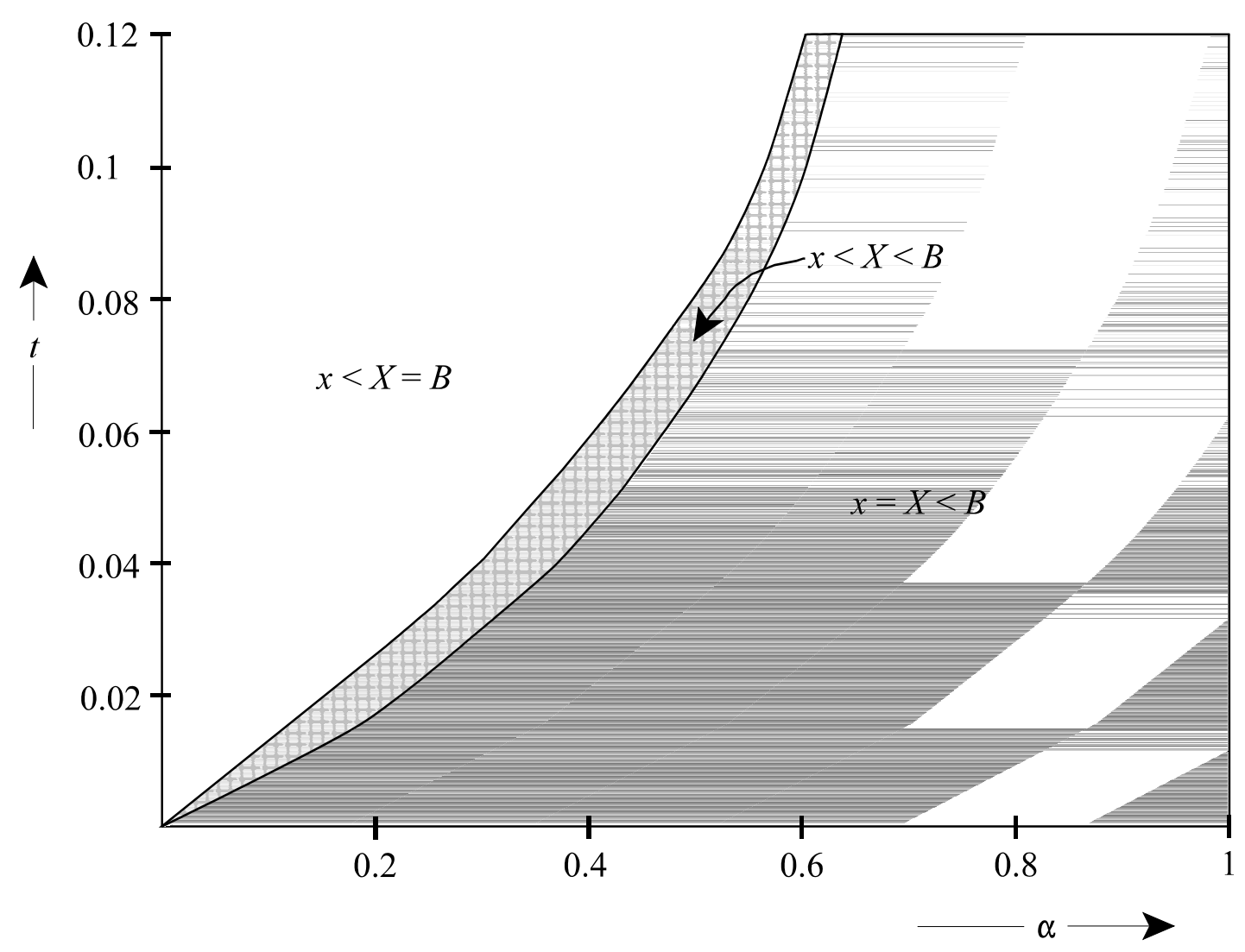

Figure 4: sorting equilibria without and with undeveloped land.

At given $t$ and sufficiently low $\alpha$, the difference in the public service between jurisdictions is relatively small and there is no undeveloped city land. Holding $t$ constant, as $\alpha$ increases, the difference in the voted public service increases, the city becomes increasingly unattractive to poor households and further increases of $\alpha$ above a critical value cause some poor households to migrate from the city to the suburb, opening up undeveloped city land. At high $\alpha$, the difference in the public service is sufficiently great that all poor households prefer to live in the suburb and to pay the higher commuting cost than to live in the city and to experience the high public service level. This progression is equivalent to moving from Figure 3(a) through Figure 3(b) to Figure 3(c). 
In deciding where to live, poor households face a trade-off between obtaining their desired public service by living in the suburb and incurring low commuting costs by living in the city. As $\alpha$ increases, the suburb becomes more attractive, but this effect can be offset by an increase in $t$, which favors living in the city; or the boundaries between the shaded regions are upward sloping.

\section{EQUILIBRIUM WITH INCOME MIXING}

An alternative to income sorting is income mixing. If income mixing is to occur whether across space or between jurisdictions - some poor households must live in the city and some rich households must live in the suburb. If this is to happen, for the rich households living in the suburb, the cost of the longer commute must be offset by the benefit of the higher public service, which requires that rich households are the majority in the suburb and poor households are the majority in the city. This is formalized in Lemma B.

LEMMA B: If some poor households live in the city and some rich households live in the suburb, rich households must form the majority in the suburb and poor households must form the majority in the city.

PROOF OF LEMMA B: The proof is by contradiction. The maintained assumption is that some poor households live in the city and some rich households live in the suburb. We need to show that the following cases are inconsistent with equilibrium: (a) rich households form the majority in the city and poor households form the majority in the suburb; (b) poor households form the majority in both jurisdictions and (c) rich households form the majority in both jurisdictions. 
We consider Case (a) first. If rich households are the majority in the city and poor households are the majority in the suburb, both income groups live in both jurisdictions. The boundary between rich and poor households occurs at radius $x$ in the city and at radius $y$ in the suburb. Rich households obtain the same utility in either jurisdiction, or

$$
\max _{g} U\left(M_{2}-b_{2 c}-g+T, g\right)=U\left(M_{2}-b_{2 s}-g_{s}+T, g_{s}\right) .
$$

Since the left-hand side evaluates utility at the optimizing choice of $g$, this implies

$$
b_{2 c} \geq b_{2 s} \text {. }
$$

Rent continuity at $x$, the above inequality and rent continuity at $y$ implies

$$
b_{1 c}=b_{2 c}-t\left(M_{2}-M_{1}\right) x \geq b_{2 s}-t\left(M_{2}-M_{1}\right) x=b_{1 s}+t\left(M_{2}-M_{1}\right)(y-x) \text {. }
$$

But $y>x$, and hence $b_{l c}>b_{l s}$. This in turn implies

$$
U\left(M_{1}-b_{1 c}-g_{c}+T, g_{c}\right)<\max _{g} U\left(M_{1}-b_{1 s}-g+T, g\right),
$$

which contradicts the assumption that poor households live in both jurisdictions.

The inconsistency associated with Cases (b) and (c) is proved similarly. ${ }^{12} \#$

With rich households forming the majority in the suburb and poor households forming the majority in the city, for a poor household in the suburb the disadvantages of the high public service level (and associated tax) and the high commuting cost must be exactly offset by the low 
rent. If there were undeveloped land in the city, land in the city would be available at the reservation price $r_{0}$ so that poor households could move from the suburban fringe to the city without a change in rent. This would benefit them because they would obtain a lower commuting cost and their favored public service level. Hence, if poor households reside in the suburb in this type of equilibrium, the city must have no undeveloped land. This result is formalized in Lemma C.

LEMMA C: If poor households live in the city and in the suburb, and some rich households live in the suburb, there is no undeveloped city land.

PROOF OF LEMMA C: The proof is by contradiction. The maintained assumption is that poor households live in the city and in the suburb, and that some rich households live in the suburb. We assume that there is undeveloped land in the city. Lemma B tells us that poor households are the majority in the city. Poor households at $X$ and $Y$ achieve equal utility, or

$$
\max _{g} U\left(M_{1}-t M_{1} X-a r_{0}-g+T, g\right)=U\left(M_{1}-t M_{1} Y-a r_{0}-g_{s}+T, g_{s}\right)
$$

Since the left-hand side evaluates utility at the optimizing choice of $g$, this is inconsistent with $X<\mathrm{Y}$. \#

There are several possible equilibrium configurations consistent with rich households living outside poor households. Because it seems the empirically relevant case and descriptively the furthest from the equilibrium with income sorting, we consider first the case when both jurisdictions contain both income groups. This case corresponds to income mixing between 
jurisdictions and across space. The boundary between rich and poor households occurs at radius $x$ in the city and at radius $y$ in the suburb

Although the qualitative equilibrium conditions continue to be those outlined in Section 2 , the relevant equations must be modified to take account of the different spatial configuration: they are presented in the Appendix. We now state the main result of this section.

THEOREM 2: In addition to the equilibrium with income sorting, there can exist equilibria with income mixing both between jurisdictions and across space. ${ }^{13}$

PROOF: The proof is by construction of an example. Households are assumed to have utility with a Cobb-Douglas form,

$$
(1-\alpha) \log _{e} c+\alpha \log _{e} g,
$$

and with parameter values as in Section 3: $M_{1}=.3, M_{2}=.6, \theta=.6, B=7, N a=\pi\left(10^{2}\right)$ and $r_{0}=0$. The hatched area of Figure 6 (see later) shows values of $\{\alpha, t\}$ for which we can calculate solutions to the equations presented in the Appendix. 


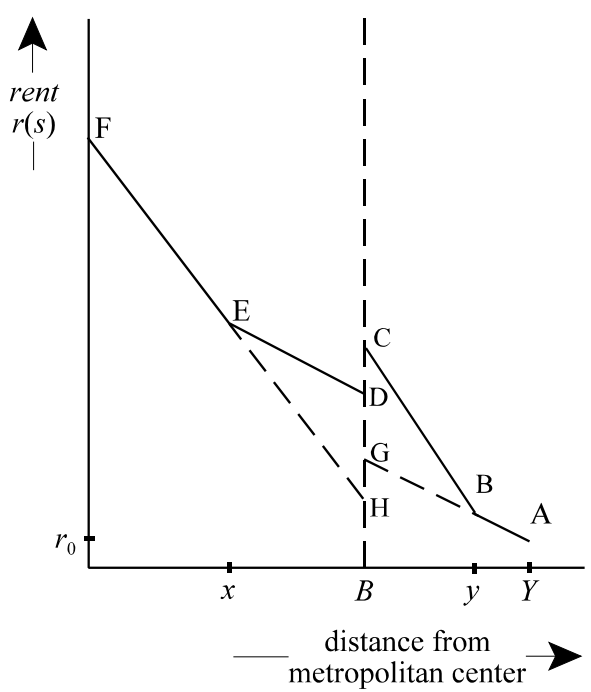

(a)

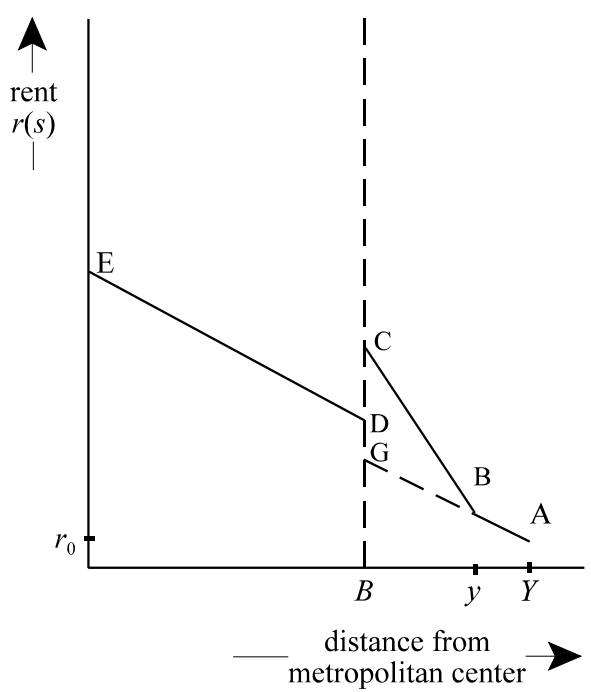

(b)

Figure 5: income mixing: (a) across space and between jurisdictions, (b) across space

Figure 5(a) shows the rent schedules when both jurisdictions contain both income groups. Poor households live at the suburban fringe $Y$ and the rent schedule is anchored there at $r_{0} . A B G$ is the bid-rent curve of poor households in the suburb and $B C$ is the bid-rent curve of rich households in the suburb. As the location moves inwards across the boundary between the suburb and the city, the public service changes from the level set by rich households to the level set by poor households: poor households are willing to pay the premium $G D$ to live in the city and $D E$ is the bid-rent curve of poor households in the city. Rich households choose the suburban public service, so that rent at the boundary has to fall by $\mathrm{CH}$ if a rich household were to be willing to live on the city's side of the boundary. $H E F$ is the bid-rent curve of a rich household in the city. The vertical distance between $D E$ and $H E$ is the difference between actual rent and the rent a rich household is willing to pay, or is the net cost to a rich suburban household of moving to a location in the city. 
What allows the equilibrium to exist with both income groups in both jurisdictions is that between $B$ and $x$ the benefit to rich households of moving closer to the metropolitan center increases faster than land prices. In particular, as the location moves from the jurisdictional boundary towards the metropolitan center, the willingness to pay of the rich household for the city location rises at rate $t M_{2}$; however the actual rent rises at the lower rate $t M_{l}$, a rate which reflects the relatively low value poor households place on a marginally smaller commute. At distance $x$ from the metropolitan center, willingness to pay equals the rent, and rich households outbid poor households for all locations closer to the metropolitan center.

As households become more sensitive to public service levels, the rich household's willingness to pay for a higher public service increases and it becomes more important for the rich to live in the suburb: HEF moves down. Rich households move to the suburb and poor households take their place in the city. At a critical sensitivity, one jurisdiction becomes homogenous in income. Figure (5b) is drawn on the assumption that the poor households are sufficiently numerous to be able to completely fill the city and spill-over into the suburb. Fiscal sorting is sufficiently strong that we have income sorting between jurisdictions but there is still income mixing across space; this corresponds to the top-right box in Figure 2.

To illustrate the equilibria with income mixing, we continue with the earlier example: households have utility functions of Cobb-Douglas form, $(1-\alpha) \log _{e} c+\alpha \log _{e} g$, and the parameter values are $M_{1}=.3, M_{2}=.6, \theta=.6, B=7, N a=\pi\left(10^{2}\right)$ and $r_{0}=0$. The hatched region in Figure 6 shows values of $\{\alpha, t\}$ for which there is an equilibrium with income mixing between jurisdictions and across space (as in Figure 5(a)). The shaded region in Figure 6 is entered by increasing $\alpha$ (given $t$ ) and corresponds to equilibria with 
income mixing across space but income sorting across jurisdictions (as in Figure 5(b)).

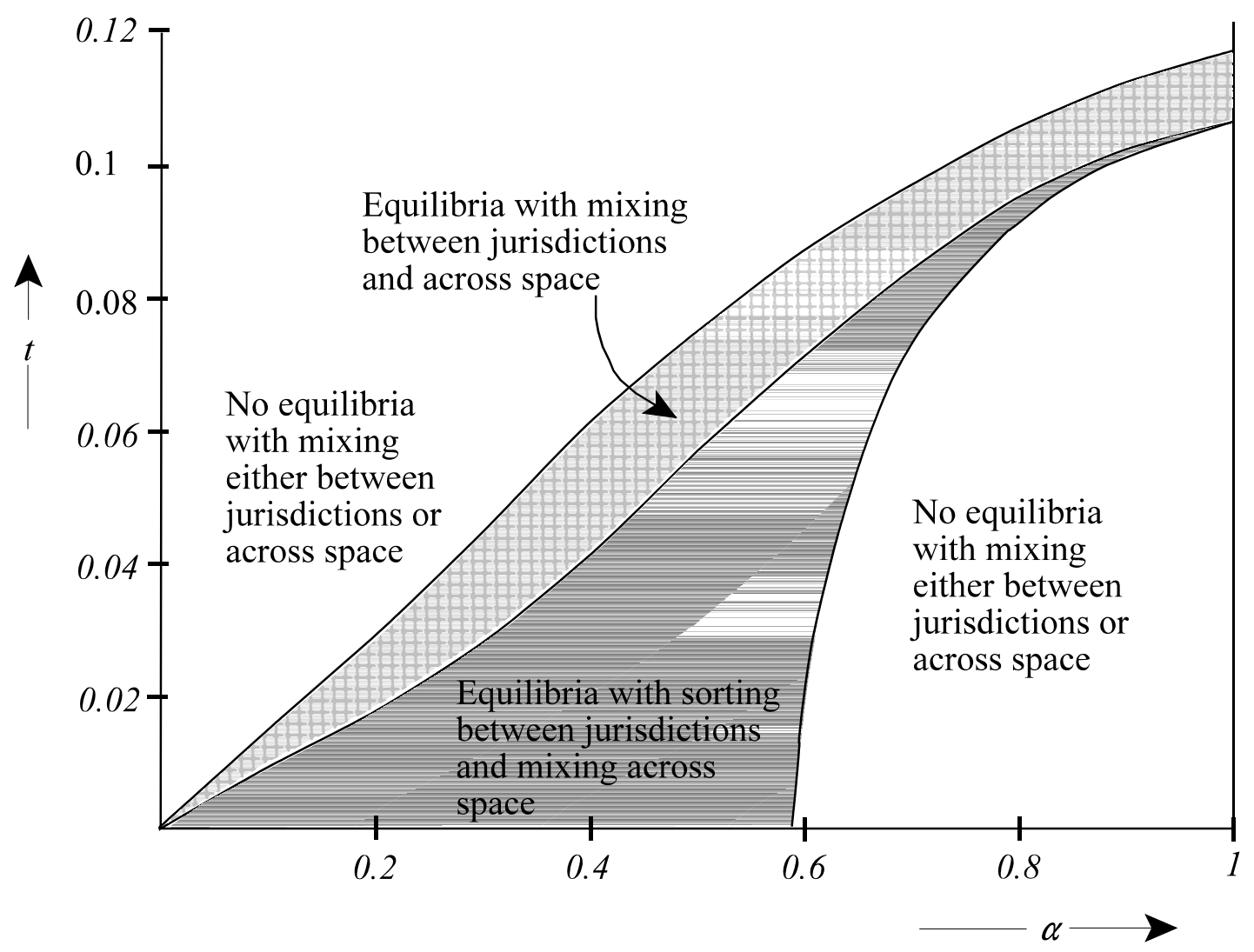

Figure 6: parameter values giving an equilibrium with income mixing.

At low values of $\alpha$, differences in the public service are relatively unimportant so that rich households cannot be induced to stay in the suburb by a potentially-higher public service. Instead, commuting considerations dominate and rich households outbid poor households for the locations closer to the metropolitan center. This is the unshaded portion at the left of Figure 6: there is no equilibrium with income mixing. The only equilibrium has income sorting.

As $\alpha$ increases (holding $t$ constant at a value below 0.106 ), differences in public service 
levels become more important so that rich households would migrate to the suburb if the public service there were higher. Above a critical value, sufficient rich households can migrate that they can form the majority and vote the higher desired public service. This is the hatched area in Figure 6 and corresponds to rent schedules as in Figure 5(a): there is an equilibrium with income mixing between jurisdictions and across space. As $\alpha$ increases further, more rich households move to the suburb to benefit from the higher public service; these rich households displace poor households to the city. Above a critical $\alpha$, the city contains no rich households. This is the shaded region in Figure 6, and corresponds to rent schedules as in Figure 5(b): there is an equilibrium with income sorting between jurisdictions and income mixing across space.

As $\alpha$ is further increased, the voted public service and tax in the suburb increase, and above a critical $\alpha$ poor households cannot afford to live in the suburb (i.e., their consumption would be negative). This is the unshaded area at the right of Figure $6:$ the only equilibrium is income sorting. ${ }^{14}$

The comparative statics of an increase in $t$ are similar. At given $\alpha$ (below 0.59) and low $t$, commuting costs for rich households are relatively unimportant compared to their taste for the public service, and all rich households live in the suburb if the public service there is higher: there is an equilibrium with income sorting between jurisdictions and income mixing across space. As $t$ increases above a critical value, we enter the hatched region: high commuting costs induce some rich households to move into the city, displacing poor households and creating income mixing between jurisdictions and across space. As $t$ increases above a second critical value, enough poor households have moved from the city that they become the majority in the suburb; equilibrium with income mixing cannot be sustained. 
In Figure 6 the region in which values of $\alpha$ and $t$ support an equilibrium in which both jurisdictions contain both income-groups is "upward sloping" from the origin. As $t$ increases, living in the city becomes more attractive to rich households. For rich households to continue to live in the suburb, their willingness to pay for their desired public service must increase, or $\alpha$ must increase.

\section{CONCLUSION}

In this paper we have placed the model of fiscal competition inside a spatial model, using a model with two jurisdictions and two income classes. We show that there is an equilibrium with income sorting, and we believe that this is the equilibrium on which most of the literature has focused. This equilibrium may contain undeveloped land. We also show that there can be another equilibria in which there is not a monotonic relationship between income and distance from the metropolitan center, and in particular there can be an equilibrium in which both jurisdictions contain households of both income levels. This second equilibrium reconciles the model of residential choice with the empirical finding of income mixing.

The equilibrium with income mixing arises because of the way land prices adjust to both fiscal differences and commuting costs. As the location moves across the boundary from the suburb into the city, land prices fall and the extent of the fall is determined by the willingness to pay of the poor households for the lower public service in the city. As the location moves closer to the metropolitan center, land prices rise at a rate which reflects the commuting savings of the poor households who live in these locations. From the perspective of a rich household in the suburb, the commuting saving of locating closer to the metropolitan center is being only partially 
capitalized into land prices. In this way, as the location moves towards the metropolitan center, the commuting saving net of the increase in land price increases for the rich household until it fully compensates for the lower public service.

Our model is necessarily stylized in order to focus on the forces which can give rise to income mixing between jurisdictions and across space. Comparative statics were performed on changing the taste for the public service $(\alpha)$ and commuting costs $(t)$ in the presence of an exogenous jurisdictional boundary $(B)$. It is relatively straightforward to do the comparative statics of a change in $B$ : for empirically reasonable values of $\alpha$ and $t$, the equilibrium with income mixing exists provided $B$ is not "too small"; the city must be sufficiently large (4 miles or more for reasonable values of $\alpha$ and $t$ ) that, by moving close to its center, the change in the commuting cost for rich households on moving from the inside of the suburb to the center of the city is sufficient to offset the cost of the lower public service. ${ }^{15}$

Current metropolitan areas have grown out of much smaller cities. Might history have played a role in selecting the equilibrium with income mixing? The key to the development of an equilibrium with income mixing is the creation of a suburb with a majority of rich households. Historically, when metropolitan populations were small compared to the size of the city area, all households lived in the city and poor households formed the majority. In de Bartolome and Ross [6] we simulate to obtain the comparative statics of an increase in the population in the presence of an exogenous jurisdictional boundary. As the population grows, or as the limit of development moves outwards, house prices rise near the metropolitan center. By moving outside the jurisdictional boundary, the rich are able to avoid the high rents in the center of the city and obtain a public service level which better meets their needs. Hence, as required for an 
equilibrium with income mixing, some rich households locate in the suburb while there is still undeveloped city land. ${ }^{16}$ As the population continues to grow, it infills the undeveloped city land and poor households are pushed into the suburb: both jurisdictions contain both income groups. 


\section{APPENDIX: EQUILIBRIUM WITH INCOME MIXING BETWEEN JURISDICTIONS}

Lemma A shows that the rich households live closer to the metropolitan center in each jurisdiction. With both income classes living in both jurisdictions, the boundary between the rich and poor households occurs in the city at radius $x$ and in the suburb at radius $y$. We use the notation and structure developed in Section 2. In particular, we continue to denote the total rent plus commuting cost of a household of income $M_{i}$ living in jurisdiction $j$ as $b_{i j}$.

1. Reservation land price: poor households live at the suburban fringe, or

$$
b_{1 s}=r_{0}+t M_{1} Y
$$

2. Rent continuity in the city at $x$ implies

$$
b_{2 c}-t M_{2} x=b_{1 c}-t M_{1} x .
$$

Rent continuity in the suburb at $y$ implies

$$
b_{2 s}-t M_{2} y=b_{1 s}-t M_{1} y \text {. }
$$

3. No migration: both poor and rich households must be indifferent between jurisdictions, or

$$
\begin{aligned}
& U\left(M_{1}-b_{1 s}-g_{s}+T, g_{s}\right)=U\left(M_{1}-b_{1 c}-g_{c}+T, g_{c}\right) \\
& U\left(M_{2}-b_{2 s}-g_{s}+T, g_{s}\right)=U\left(M_{2}-b_{2 c}-g_{c}+T, g_{c}\right) .
\end{aligned}
$$


4. Determination of the public service. Lemma B implies:

$$
\text { in the city: } \quad g_{c}=\underset{g}{\operatorname{argmax}} U_{c}\left(M_{1}-b_{1 c}-g+T, g\right)
$$

$$
\text { in the suburb: } g_{s}=\underset{g}{\operatorname{argmax}} U_{c}\left(M_{2}-b_{2 s}-g+T, g\right) \text {. }
$$

5. Land equilibrium: Lemma $\mathrm{C}$ implies there is no undeveloped land, or

$$
\begin{aligned}
& \pi x^{2}+\pi\left(y^{2}-B^{2}\right)=(1-\theta) N a \\
& \pi Y^{2}=N a .
\end{aligned}
$$

6. Model closure. The lump-sum transfer $T$ is used to return rent to households, or

$$
\begin{aligned}
T=\frac{1}{N}\left[\int_{0}^{x} \frac{b_{2 c}-t M_{2} d}{a}\right. & 2 \pi d d d+\int_{x}^{B} \frac{b_{1 c}-t M_{1} d}{a} 2 \pi d d d \\
& \left.+\int_{B}^{y} \frac{b_{2 s}-t M_{2} d}{a} 2 \pi d d d++\int_{y}^{Y} \frac{b_{1 s}-t M_{1} d}{a} 2 \pi d d d\right] .
\end{aligned}
$$

The equilibrium values of the ten variables $b_{2 c}, b_{1 c}, b_{2 s}, b_{1 s}, g_{u}, g_{s}, x, y, Y$ and $T$ solve Equations (A.1) - (A.10). In addition, the values must satisfy (1) the assumed majorities in each jurisdiction ${ }^{17}$ (2) the assumed ordering of distances $0<x<B<y<Y$. and (3) nonnegative consumption. 


\section{REFERENCES}

1. W. Alonso, Location and Land Use: Toward a General Theory of Land Rent, Harvard University Press, Cambridge 1964.

2. E. Berglas, On the Theory of Clubs, Papers and Proceedings of the American Economic Association 66 (1976) 116-121.

3. E. Berglas, Distribution of Tastes and Skills, and the Provision of Local Public Goods, Journal of Public Economics 6 (1976) 409-423.

4. E. Berglas, D. Pines, Clubs, Local Public Goods and Transportation Models: a Synthesis, Journal of Public Economics 15 (1981) 141-162.

5. J.K. Brueckner, Tastes, Skills and Local Public Goods, Journal of Urban Economics 35 (1994) 201-220.

6. C.A.M.de Bartolome, S.L. Ross, A Monocentric Urban Model with City and Suburban Governments, unpublished mimeo, 2000.

7. B. Elickson, Jurisdictional Fragmentation and Residential Choice, Papers and Proceedings of the American Economic Association 61 (1971) 334-339.

8. D. Epple, G.J. Platt, Equilibrium and Local Redistribution in an Urban Economy when Households Differ in Both Preferences and Income, Journal of Urban Economics 43 (1998) 23-51.

9. D. Epple, R. Filimon, T. Romer, Equilibrium among Local Jurisdictions: Toward an Integrated Treatment of Voting and Residential Choice, Journal of Public Economics 24 (1984) 281-308. 
10. D. Epple, R. Filimon, T. Romer, Existence of Voting and Housing Equilibrium in a System of Communities with Property Taxes, Regional Science and Urban Economics 23 (1993), 585-610.

11. E.L. Glaeser, M.E. Kahn, J. Rappaport, Why do the poor live in the cities?, National Bureau of Economic Research Working Paper \# 7636 (2000).

12. S.F. LeRoy, J. Sonstelie, Paradise Lost and Regained: Transportation, Innovation, Income and Residential Location, Journal of Urban Economics 13 (1983) 67-89.

13. M.C. McGuire, Group Segregation and Optimal Jurisdictions, Journal of Political Economy 82 (1974) 112-132.

14. M.C. McGuire, Group Composition, Collective Consumption, and Collaborative Production, American Economic Review 81 (1991) 1391-1407.

15. E.S. Mills, An Aggregative Model of Resource Allocation in a Metropolitan Area, Papers and Proceedings of the American Economic Association 57 (1967) 197-210.

16. A. Montesano, A Restatement of Beckmann's Model on the Distribution of Urban Rent and Residential Density, Journal of Economic Theory 4 (1972) 329-354.

17. R. Muth, Cities and Housing, University of Chicago Press, Chicago 1969.

18. T. Nechyba, A Computable General Equilibrium Model of Intergovernmental Aid, Journal of Public Economics 62 (1996) 363-397.

19. H. Pack, J.Pack, Metropolitan Fragmentation and Suburban Homogeneity, Urban Studies 14 (1977) 191-201.

20. H. Pack, J.Pack, Metropolitan Fragmentation and Local Public Expenditures, National Tax Journal 31 (1978) 349-362. 
21. J. Persky, Suburban Income Inequality: Three Theories and a Few Facts, Regional Science and Urban Economics 20 (1990) 125-137.

22. S.L. Ross, J. Yinger, Sorting and Voting: a Review of the Literature on Urban Public Finance, in: P. Cheshire, E.S. Mills (Ed.), Handbook of Urban and Regional Economics, Vol 3, North Holland, Amsterdam 1999, pp.2001-2060.

23. J.E. Stigltiz, Public Goods in Open Economies with Heterogeneous Individuals, in J-F Thisse, H.G. Zoller (Ed.), Location Analysis of Public Facilities, North Holland, Amsterdam, 1983, pp. 55-78.

24. C.M.Tiebout, A Pure Theory of Local Expenditures, Journal of Political Economy 94 (1956) 416-424.

25. W.C. Wheaton, Consumer Mobility and Community Tax Bases, Journal of Public Economics 4 (1975) 377-384.

26. W.C. Wheaton, Income and Urban Residence: An Analysis of Consumer Demand for Location, American Economic Review 67 (1977) 620-631.

27. M. Wooders, Equilibria, the Core and Jurisdictional Structures in Economies with a Local Public Good, Journal of Economic Theory 18 (1978) 328-348.

28. J. Yinger, Capitalization and the Theory of Local Public Finance, Journal of Political Economy 90 (1982) 917-943. 
NOTE TO REFEREE: NOT FOR PUBLICATION

I show on the next few pages:

(1) The proof of Theorem 1.

(2) The proofs of Lemma B for Cases (b) and (c). Footnote 12 refers 


\section{PROOF OF THEOREM 1}

There are 5 potential cases, determined by the number of rich households relative to the city's area. We note that positive rents imply $T>0$.

Case 1: poor households are the majority in both jurisdictions; $N a(1-\theta)<1 / 2 \pi B^{2}$.

Poor households choose the public service in each jurisdiction. No migration requires

$$
\max _{g} U\left(M_{1}-b_{1 c}-g+T, g\right)=\max _{g} U\left(M_{1}-b_{1 s}-g+T, g\right)
$$

Hence $b_{1 c}=b_{1 s}$. It is "as if" there is a single jurisdiction for which it is readily shown that an equilibrium exists.

Case 2: rich households form the majority in the city but do not completely fill the city, and only poor households live in the suburb: $1 / 2 \pi B^{2} \leq N a(1-\theta)<\pi B^{2}$.

The proof shows that one of the three situations shown in Figure 3 must exist. We ignore the self-selection constraint for rich households until the end. Our proof strategy is to start by assuming that there is no undeveloped city land $(X=B$ or the structure of Figure 3(a)) to calculate the rent required at the inside of the city's boundary for poor households to achieve the same utility in each jurisdiction. If the required rent is greater or equal to $r_{0}$, we have a equilibrium (provided rich-households self-select). If the required rent is less than $r_{0}$, our strategy is to reduce $X$ either until the required rent is $r_{0}$ (Figure $3(\mathrm{~b})$ ) or until $X=x$ (Figure 3(c)): in either case we have a equilibrium (provided rich households self-select). Finally, we show that there is self-selection for rich households.

Formally, we need to show that there exist values of $b_{2 c}, b_{1 c}, b_{1 s}, g_{c}, g_{s}, x, X, Y$ and $T$ which solve the following relationships: 
Land price at suburban fringe: $b_{1 s}=r_{0}+t M_{1} Y$.

Land price at boundary of development in city: ${ }^{18}$

$$
\left.\begin{array}{rl}
\text { either } X=B: & b_{1 c} \geq r_{0}+t M_{1} B \\
\text { or } X<B: & b_{1 c}=r_{0}+t M_{1} X
\end{array}\right\}
$$

Rent continuity at $x$ :

$$
\left.\begin{array}{rl}
\text { either } x<X: b_{2 c} & =b_{1 c}+t\left(M_{2}-M_{1}\right) x \\
\text { or } x=X: b_{2 c} & =r_{0}+t M_{2} x
\end{array}\right\}
$$

Using Equation (A.2), this is rewritten as:

$$
b_{2 c}=b_{1 c}+t\left(M_{2}-M_{1}\right) x .
$$

No migration for poor households:

$$
\left.\begin{array}{r}
\text { either } x<X: U\left(M_{1}-b_{1 s}-g_{s}+T, g_{s}\right)=U\left(M_{1}-b_{1 c}-g_{c}+T, g_{c}\right) \\
\quad \text { or } x=X: U\left(M_{1}-b_{1 s}-g_{s}+T, g_{s}\right) \geq U\left(M_{1}-b_{1 c}-g_{c}+T, g_{c}\right) .
\end{array}\right\}
$$

No migration for rich households: this is considered later.

Voting in city: denoting $U_{i}$ as the derivative of utility with respect to the $i$ th argument,

$$
U_{1}\left(M_{2}-b_{2 c}-g_{c}+T, g_{c}\right)=U_{2}\left(M_{2}-b_{2 c}-g_{c}+T, g_{c}\right) \text {. }
$$

Voting in suburb: $\quad U_{1}\left(M_{1}-b_{1 s}-g_{s}+T, g_{s}\right)=U_{2}\left(M_{1}-b_{1 s}-g_{s}+T, g_{s}\right)$.

Land market

$$
\begin{aligned}
& \pi x^{2}=(1-\theta) N a \\
& \pi X^{2}+\pi\left(Y^{2}-B^{2}\right)=N a .
\end{aligned}
$$


Return of rents:

$$
T=\frac{1}{N}\left[\int_{0}^{x} \frac{b_{2 c}-t M_{2} d}{a} 2 \pi d d d+\int_{x}^{X} \frac{b_{1 c}-t M_{1} d}{a} 2 \pi d d d+\int_{B}^{Y} \frac{b_{1 s}-t M_{1} d}{a} 2 \pi d d d\right]
$$

We note that Equation (A.7) implies that $x$ is determined by the number of rich households and that we can treat it as a predetermined constant. We show first that Equations (A.1), (A.3), (A.5), (A.6), (A.8) and (A.9) can be implicitly solved to express $b_{2 c}, b_{1 s}, g_{c}, g_{s}, Y$ and $T$ as continuous functions of $b_{1 c}$ and $X$; these functions are written as $b_{2 c}\left(b_{1 c} ; X\right), b_{1 s}\left(b_{1 c} ; X\right)$, $g_{c}\left(b_{1 c} ; X\right), g_{s}\left(b_{l c} ; X\right), Y\left(b_{1 c} ; X\right)$ and $T\left(b_{l c} ; X\right)$. Then we show that $b_{l c}$ and $X$ can be found so that Equations (A.2) and (A.4) are satisfied. Turning first to the implicit functions:

LEMMA D: Provided $b_{1 c}$ is less than or equal to the implicit value of $b_{1 s}$, Equations (A.1), (A.3), (A.5), (A.6), (A.8) and (A.9) can be solved to express $b_{2 c}, b_{1 s}, g_{c}, g_{s}, Y$ and $T$ as continuous implicit functions of $b_{1 c}$ and $X$.

PROOF: We establish that (a) given values for $b_{1 c}$ and $X$, Equations (A.1), (A.3), (A.5), (A.6), (A.8) and (A.9) can be solved for $b_{2 c}, b_{1 s}, g_{c}, g_{s}, Y$ and $T$ and that (b) the Jacobian is non-zero. This enables us to use the Implicit Function Theorem.

Given $X$, Equation (A8) gives the value of $Y$ :

$$
Y=\sqrt{\frac{N a}{\pi}+B^{2}-X^{2}}
$$

Using Equation (A.1), the restriction $b_{l c} \leq b_{l s}$ implies that we restrict attention to values of $b_{l c}$ and $X$ such that 


$$
b_{1 c} \leq r_{0}+t M_{1} \sqrt{\frac{N a}{\pi}+B^{2}-X^{2}}
$$

Knowing $x$ and $Y$, and given $b_{1 c}$, Equation (A.1) and (A.3) enable $b_{1 s}$ and $b_{2 c}$ to be directly calculated. Integrating Equation (A.9),

$$
\begin{gathered}
T=\frac{2 \pi}{N a}\left[\frac{b_{2 c} x^{2}}{2}-\frac{t M_{2} x^{3}}{3}+\frac{b_{1 c} X^{2}}{2}-\frac{t M_{1} X^{3}}{3}-\frac{b_{1 c} x^{2}}{2}+\frac{t M_{1} x^{3}}{3}\right. \\
\left.+\frac{b_{1 s} Y^{2}}{2}-\frac{t M_{1} Y^{3}}{3}-\frac{b_{1 s} B^{2}}{2}+\frac{t M_{1} B^{3}}{3}\right] .
\end{gathered}
$$

Given $X$ and $b_{1 c}$ and knowing $x, Y, b_{1 s}$ and $b_{2 c}, T$ can be calculated.

Knowing $b_{l s}$ and $T$, the strict concavity of the utility function implies that Equation (A.6) can be solved for $g_{s}$ provided $M_{1}-b_{l s}+T>0$; this inequality is ensured by the assumption that poor households have sufficient income to live in the suburb. Similarly, knowing $b_{2 c}$ and $T$, Equation (A5) implies a value for $g_{c}$ provided $M_{2}-b_{2 c}+T>0$; this inequality is ensured by using Equation (A.3), $t x<t Y<1$ and the restriction $b_{1 c} \leq b_{1 s,}$

$$
M_{2}-b_{2 c}+T=M_{1}-b_{1 c}+(1-t x)\left(M_{2}-M_{1}\right)+T>M_{1}-b_{1 c}+T \geq M_{1}-b_{1 s}+T>0 .
$$

We now consider the Jacobian determinant associated with Equations (A.1), (A.3), (A.5), (A.6), (A.8) and (A.9). This is:

$$
-2 \pi Y\left(U_{11}(1 s)-2 U_{12}(1 s)+U_{22}(1 s)\right)\left(U_{11}(2 c)-2 U_{12}(2 c)+U_{22}(2 c)\right)
$$

where the subscripts on $U(.$.$) indicate the position with respect to which the derivative is taken$ and the numbers $i j$ in the parenthesis indicate that the function is evaluated for a household of 
income $M_{i}$ in jurisdiction $j$. The derivatives exist because $M_{1}-b_{1 s}+T>0$ and $M_{2}-b_{2 c}+T>0$

(see earlier). The strict concavity of the utility function implies that each term in parenthesis is strictly negative, or that the Jacobian determinant is non-zero.

Hence, by the Implicit Function Theorem and provided $b_{l c} \leq b_{l s}$, it is possible to write $b_{2 c}, b_{1 s}, g_{c}, g_{s}, Y$ and $T$ as continuous implicit functions of $b_{1 c}$ and $X$.

We now use these functions to define the difference in the utility which would be achieved by a poor household in the suburb and in the city (if Equations (A.1),(A.3), (A.5), (A.6), (A.8) and (A.9) are solved at a given $b_{l c}$ and $X$ ) :

$$
\begin{aligned}
Q\left(b_{1 c} ; X\right) \equiv U\left(M_{1}-b_{1 s}\left(b_{1 c} ; X\right)\right. & \left.-g_{s}\left(b_{1 c} ; X\right)+T\left(b_{1 c} ; X\right), g_{s}\left(b_{1 c} ; X\right)\right) \\
& -U\left(M_{1}-b_{1 c}-g_{c}\left(b_{1 c} ; X\right)+T\left(b_{1 c} ; X\right), g_{c}\left(b_{1 c} ; X\right)\right) .
\end{aligned}
$$

Provided there is self-selection for the rich households, equilibrium requires that values of $X$ and $b_{I c}$ can be found such that Equations (A.2) and (A.4) are jointly satisfied, or:

either $x<X=B: \quad$ there is no undeveloped city land and poor households achieve equal utility in each jurisdiction, or there exists $b^{A}$ such that $b^{A} \geq r_{0}+t M_{1} B$ and $Q\left(b^{A} ; B\right)=0$;

or $\quad x<X<B:$ there is undeveloped city land and poor households achieve equal utility in each jurisdiction, or there exists $X^{A}$ such that $x<X^{A}<B$ and $Q\left(r_{0}+t M_{1} X^{A} ; X^{A}\right)=0$

or $\quad x=X<B:$ there are no poor households in the city, or $Q\left(r_{0}+t M_{1} x ; x\right) \geq 0$. 
To show that one of these situations must arise, first consider $X=B$. In this case, Equations (A.1) and (A.8) imply that $Y$ and $b_{1 s}$ are constants, independent of $b_{1 c}$; denote this value of $b_{1 s}$ as $b_{1 s}{ }^{*}$ and first choose $b_{1 c}$ to equal $b_{1 s}{ }^{*}$. At this value of $b_{1 c}$, Equation (A.1) implies $b_{1 c}=b_{1 s}^{*}=r_{0}+t M_{1} Y>r_{0}+t M_{1} B$, or Equation (A.2) is satisfied. Using Equation (A.3) and $t x<t Y<1$,

$$
M_{2}-b_{2 c}+T=M_{1}-b_{1 c}+(1-t x)\left(M_{2}-M_{1}\right)+T>M_{1}-b_{1 c}+T
$$

hence when $b_{1 c}=b_{1 s}, M_{2}-b_{2 c}+T>M_{1}-b_{1 s}+T$, and normality implies $g_{c}>g_{s}$. Remembering that poor households choose the public service in the suburb, $Q\left(b_{1 s}^{*} ; B\right)>0$. Second, maintaining $X=B$, lower $b_{l c}$ from $b_{l s}{ }^{*}$ to $r_{0}+t M_{1} B$. Equation (A.2) continues to be satisfied. $b_{1 c} \leq b_{1 s}$ so that all variables change continuously. $Q\left(b_{1 c} ; B\right)$ changes continuously so that either Case A: there is some $b_{l c}$ denoted $b^{A}, r_{0}+t M_{1} B \leq b^{A}<b_{1 s}^{*}$, for which $Q\left(b^{A} ; B\right)=0$. This is an equilibrium (provided there is self-selection of rich households). Or Case B: $Q\left(r_{0}+t M_{1} B ; B\right)>0$

If Case B is relevant, lower $X$ from $B$ to $x$ and change $b_{1 c}$ so that $b_{1 c}=r_{0}+t M_{1} X$.

Equation A.2 is satisfied by construction. As these changes are effected, $Y$ and $b_{1 s}$ are increasing (Equations (A.8) and (A.1)) and $b_{1 c}$ is decreasing, so that $b_{1 c} \leq b_{1 s}$ and all variables change continuously. Hence either Case B1: there is some $X$ denoted $X^{A}, x \leq X^{A}<B$, for which $Q\left(r_{0}+t M_{1} X^{A} ; X^{A}\right)=0$. This is an equilibrium (provided there is self-selection for rich households). Or Case B2: $Q\left(r_{0}+t M_{1} x ; x\right)>0$. This is an equilibrium (provided there is self- 
selection for rich households).

To confirm the self-selection of rich households: if a rich household were to move to the suburb, he would locate at the inner suburban boundary and pay rent $b_{1 s}-t M_{1} B$, or his total rent plus commuting cost would be $b_{1 s}-t M_{1} B+t M_{2} B$. Using Equation (A.3) and the implicit result that $b_{1 c}<b_{1 s}$

$$
b_{2 c}=b_{1 c}+t\left(M_{2}-M_{1}\right) x<b_{1 s}+t\left(M_{2}-M_{1}\right) B .
$$

Because he chooses the city's public service and pays less rent plus commuting cost, the rich household achieves higher utility in the city than he could achieve by moving to the suburb.

Case 3: rich households live in the city, poor households live in the suburb, there is no undeveloped land and no income overlap: $\pi B^{2}=N a(1-\theta)$.

This case is straightforward and is omitted for brevity. 
Case 4: rich households fill the city and live in both jurisdictions, and poor households form the majority in the suburb: $\pi B^{2}<N a(1-\theta)<\frac{1}{2} \pi\left(Y^{2}+B^{2}\right)$.

The proof is similar to that for Case 2. The procedure is to find a rent schedule which ensures equilibrium. Rich households choose the city's public service and have lower commuting costs if they locate in the city. Ceteris paribus rich households therefore prefer the city and at equilibrium (if it exists) there is no undeveloped land in the city (the proof is similar to that in Lemma C). Denote the distance from the metropolitan center to the boundary between the rich and poor households in the suburb as $y$. The equations which define equilibrium are written as:

Land price at suburban fringe: $\quad b_{1 s}=r_{0}+t M_{1} Y$.

Land price at boundary in city: $\quad b_{2 c} \geq r_{0}+t M_{2} B$.

Rent continuity at $y: \quad b_{2 s}=b_{1 s}+t\left(M_{2}-M_{1}\right) y$.

No migration for poor households: this is considered later.

No migration for rich households: $U\left(M_{2}-b_{2 c}-g_{c}+T, g_{c}\right)=U\left(M_{2}-b_{2 s}-g_{s}+T, g_{s}\right)$.

Voting in the city: denoting $U_{i}$ as the derivative of utility with respect to the $i$ th argument,

$$
U_{1}\left(M_{2}-b_{2 c}-g_{c}+T, g_{c}\right)=U_{2}\left(M_{2}-b_{2 c}-g_{c}+T, g_{c}\right) \text {. }
$$


Voting in the suburb: $U_{1}\left(M_{1}-b_{1 s}-g_{s}+T, g_{s}\right)=U_{2}\left(M_{1}-b_{1 s}-g_{s}+T, g_{s}\right)$.

Land market: $\quad \pi y^{2}=(1-\theta) N a$;

$\pi Y^{2}=N a$.

Return of rents:

$$
T=\frac{1}{N}\left[\int_{0}^{B} \frac{b_{2 c}-t M_{2} d}{a} 2 \pi d d d+\int_{B}^{y} \frac{b_{2 s}-t M_{2} d}{a} 2 \pi d d d+\int_{y}^{Y} \frac{b_{1 s}-t M_{1} d}{a} 2 \pi d d d\right]
$$

To show the existence of equilibrium, we need to show that we can find values of $b_{2 c}, b_{2 s}, b_{1 s}, g_{c}$, $g_{s}, y, Y$ and $T$ which solve Equations (A.10)-(A.18).

First, we note that Equations (A.10), (A.12), (A.16) and (A.17) form a subset of equations which can be solved for $Y, b_{1 s}, y, b_{2 s}$ : for the remainder of the proof we search for an equilibrium value of $b_{2 c}$ and treat as $Y, b_{1 s}, y, b_{2 s}$ as predetermined constants. Second, we note that Equations (A.14), (A.15) and (A.18) can be implicitly solved to express $g_{c}, g_{s}$ and $T$ as functions of $b_{2 c}$; these functions are written as $g_{c}\left(b_{2 c}\right), g_{s}\left(b_{2 c}\right)$ and $T\left(b_{2 c}\right)$. This is shown in Lemma E below.

LEMMA E: Provided $b_{2 c}$ is less than or equal to the implicit value of $M_{2}+T$, Equations (A.14), (A.15) and (A.18) enable $g_{c}, g_{s}$ and $T$ to be expressed as continuous implicit functions of $b_{2 c}$.

PROOF: The proof uses the Implicit Function Theorem. First we establish that, given a value for $b_{2 c}$, Equations (A.14), (A.15) and (A.18) can be solved for $g_{c}, g_{s}$ and $T$. Then we establish that the Jacobian is non-zero.

Given values of $b_{2 c}$ and the inferred values for $Y, b_{1 s}, y, b_{2 s}$, Equation (A.18) is integrated 
to determine a numerical value for $T$. The strict concavity of the utility functions ensures that Equation (A.15) can be solved for $g_{s}$ provided $M_{1}-b_{1 s}+T>0$; this inequality is ensured by the assumption that poor households have sufficient income to live in the suburb. Similarly, Equation (A.14) can be solved for $g_{c}$ provided $M_{2}-b_{2 c}+T>0$; this inequality is ensured by assured by the restriction $b_{2 c} \leq M_{2}+T$.

The Jacobian determinant associated with Equations (A.14), (A.15) and (A.18) is

$$
\left(U_{11}(1 s)-2 U_{12}(1 s)+U_{22}(1 s)\right)\left(U_{11}(2 c)-2 U_{12}(2 c)+U_{22}(2 c)\right)
$$

where the subscripts on $U(.$.$) indicate the position with respect to which the derivative is taken and$ the numbers $i j$ in the parenthesis indicate that the function is evaluated for a household of income $M_{i}$ in jurisdiction $j$. The derivatives exist because $M_{1}-b_{1 s}+T>0$ and $M_{2}-b_{2 c}+T>0$ (see earlier). The strict concavity of the utility function implies that each term in parenthesis is strictly negative, or the Jacobian in non-zero. Hence, by the Implicit Function Theorem and provided $b_{2 c} \leq$ $M_{2}+T$, it is possible to write $g_{c}, g_{s}$ and $T$ as continuous functions of $b_{2 c}$.

We now use these functions to define the difference in utility which would be achieved by a rich household in the city and in the suburb (given $b_{2 c}$ and if Equations (A.11) and (A.13) are not imposed):

$$
R\left(b_{2 c}\right) \equiv U\left(M_{2}-b_{2 c}-g_{c}\left(b_{2 c}\right)+T\left(b_{2 c}\right), g_{c}\left(b_{2 c}\right)\right)-U\left(M_{2}-b_{2 s}-g_{s}\left(b_{2 c}\right)+T\left(b_{2 c}\right), g_{s}\left(b_{2 c}\right)\right) \text {. }
$$

To show the existence of equilibrium, we need to show that there is a value of $b_{2 c}$ which satisfies Inequality (A.11) and ensures that $R\left(b_{2 c}\right)=0$. 
First choose $b_{2 c}$ to equal $b_{2 s}$. Equations (A.10) and (A.12) imply

$$
b_{2 s}=b_{1 s}+t\left(M_{2}-M_{1}\right) y=r_{0}+t M_{1} Y+t\left(M_{2}-M_{1}\right) y=r_{0}+t M_{2} y+t M_{1}(Y-y)>r_{0}+t M_{2} B .
$$

Hence, when $b_{2 c}=b_{2 s}$, Inequality (A.11) is satisfied. Using Equation (A.12) and ty $<t Y<1$,

$$
\begin{aligned}
M_{2}-b_{2 s}+T=M_{2}-b_{1 s}-t\left(M_{2}-M_{1}\right) y+T & \\
& =M_{1}-b_{1 s}+(1-t y)\left(M_{2}-M_{1}\right)+T>M_{1}-b_{1 s}+T .
\end{aligned}
$$

Hence, when $b_{2 c}=b_{2 s}, M_{2}-b_{2 c}+T>M_{1}-b_{1 s}+T$; normality implies $g_{c}>g_{s}$ and hence, remembering that rich households choose the city's public service, $R\left(b_{2 s}\right)>0$.

The next step involves increasing $b_{2 c}$ above $b_{2 s}$ (but maintaining $b_{2 c} \leq M_{2}+T$ ) and considering the induced change in the utilities of rich suburban and city households. Consider rich households in the suburb: using Inequality (A.19), $M_{2}-b_{2 s}+T>M_{1}-b_{1 s}+T$. The assumption that poor households can afford to live in the suburb implies $M_{1}-b_{1 s}+T>0$, and hence, as $g_{s}$ is chosen by poor households, $g_{s}>0$ and $M_{1}-b_{1 s}-g_{s}+T>0$. Therefore a rich household in the suburb achieves utility $U\left(M_{2}-b_{2 s}-g_{s}+T, g_{s}\right)$ with $M_{2}-b_{2 s}-g_{s}+T>0$ and $g_{s}>0$

Consider now the effect of increasing $b_{2 c}$ on the utility of rich households in the city. Noting that $Y, y, b_{1 s}$ and $b_{2 s}$ are predetermined or constant, integrating Equation (A.18) (and using $N a=\pi Y^{2}$ ) gives

$$
T=A+\frac{B^{2}}{Y^{2}} b_{2 c}
$$


where $\mathrm{A}$ is a constant. Therefore

$$
M_{2}-b_{2 c}+T=M_{2}-\left(1-\frac{B^{2}}{Y^{2}}\right) b_{2 c}+A,
$$

or, as $b_{2 c}$ increases, $M_{2}-b_{2 c}+T$ decreases. As $b_{2 c} \rightarrow\left(M_{2}+A\right) /\left(1-\left(B^{2} / Y^{2}\right)\right), M_{2}-b_{2 c}+T \rightarrow 0$ and hence $g_{c} \rightarrow 0$. Therefore the properties of the utility function imply

$$
\underset{b_{2 c}}{\stackrel{\operatorname{Lim}_{2}+A}{1-\frac{B^{2}}{Y^{2}}} \quad \max } g\left(U\left(M_{2}-b_{2 c}-g+A+\frac{B^{2}}{Y^{2}} b_{2 c}, g\right)\right]<U\left(M_{2}-b_{2 s}-g_{s}+T, g_{s}\right)
$$

or

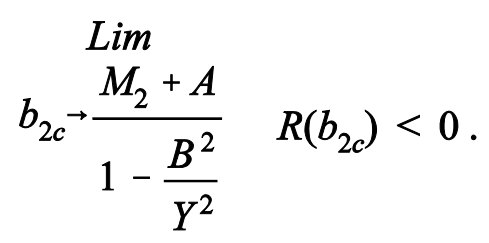

By continuity, there exists some $b_{2 c}$ denoted $b^{B}, b_{2 s} \leq b^{B}<\left(M_{2}+A\right) /\left(1-\left(B^{2} / Y^{2}\right)\right)$, such that $R\left(b^{B}\right)=0$. This is an equilibrium (provided self-selection is satisfied).

To show self-selection: if a poor household were to move to the city, he would locate just inside the city boundary and pay rent $b_{2 c}-t M_{2} B$; his total rent plus commuting cost would be $b_{2 c}-t M_{2} B+t M_{1} B$. Using Equation (A.12) and the implicit result above that $b_{2 s}<b_{2 c}$,

$$
b_{1 s}=b_{2 s}-t\left(M_{2}-M_{1}\right) y<b_{2 c}-t\left(M_{2}-M_{1}\right) B .
$$

Because he chooses the suburb's public service and pays less rent plus commuting cost, the poor household achieves more utility in the suburb than he could achieve by moving to the city. 
Case 5: rich households form the majority in both jurisdictions: $\frac{1}{2} \pi\left(Y^{2}+B^{2}\right) \leq N a(1-\theta)$.

If rich households are the majority in both jurisdictions, they choose the public service level in each jurisdiction to maximize their utility, and equilibrium requires

$$
\max _{g} U\left(M_{2}-b_{2 c}-g+T, g\right)=\underset{g}{\max } U\left(M_{2}-b_{2 s}-g+T, g\right)
$$

or $b_{2 c}=b_{2 s}$ and $g_{c}=g_{s}$. It is "as if" there is a single jurisdiction for which an equilibrium is readily shown to exist. 


\section{PROOF OF LEMMA B FOR CASES (b) AND (c).}

Case (b)poor households form the majority in both jurisdictions. A poor household obtains the same utility in the city and in the suburb, or

$$
\underset{g}{\max } U\left(M_{1}-b_{1 c}-g+T, g\right)=\max _{g} U\left(M_{1}-b_{1 s}-g+T, g\right) .
$$

Hence $b_{1 c}=b_{1 s}$ and $g_{c}=g_{s}$. There are two subcases:

Case (b.1): poor households live in both jurisdictions and rich households live only in the suburb. The boundary between rich and poor households in the suburb has radius $y$. Rent continuity in the suburb ( and $b_{l s}=b_{l c}$ ) implies:

$$
b_{2 s}=b_{1 s}+t\left(M_{2}-M_{1}\right) y=b_{1 c}+t\left(M_{2}-M_{1}\right) y>b_{1 c}
$$

This (and $\left.g_{c}=g_{s}\right)$ in turn implies

$$
U\left(M_{2}-b_{1 c}-g_{c}+T, g_{c}\right)>U\left(M_{2}-b_{2 s}-g_{s}+T, g_{s}\right)
$$

If a rich household were to migrate to the city's center, he would pay rent $b_{1 c}$. Therefore the inequality implies that a rich household can achieve more utility by moving, which is inconsistent with equilibrium. 
Case (b.2): poor and rich households live in both jurisdictions. The boundary between rich and poor households in the city has radius $x$ and in the suburb has radius $y$. Rent continuity in the suburb and city (and $b_{1 s}=b_{l d}$ ) implies:

$$
b_{2 s}=b_{1 s}+t\left(M_{2}-M_{1}\right) y=b_{1 c}+t\left(M_{2}-M_{1}\right) y=b_{2 c}+t\left(M_{2}-M_{1}\right)(y-x)>b_{2 c} .
$$

This (and $g_{c}=g_{s}$ ) in turn implies

$$
U\left(M_{2}-b_{2 c}-g_{c}+T, g_{c}\right)>U\left(M_{2}-b_{2 s}-g_{s}+T, g_{s}\right)
$$

which is inconsistent with the assumption that rich households live in both jurisdictions.

Case (c): rich households form the majority in both jurisdictions. A rich household obtains the same utility in the city or in the suburb, or

$$
\left.\max _{g} U\left(M_{2}-b_{2 c}-g+T, g\right)\right]=\max _{g} U\left(M_{2}-b_{2 s}-g+T, g\right)
$$

Hence $b_{2 c}=b_{2 s}$ and $g_{c}=g_{s}$. There are two subcases:

Case (c.1): poor households live only in the city. The boundary between rich and poor households in the city has radius $x$. Rent continuity at $x$ (and $b_{2 c}=b_{2 s}$ ) implies:

$$
b_{1 c}=b_{2 c}-t\left(M_{2}-M_{1}\right) x=b_{2 s}-t\left(M_{2}-M_{1}\right) x>b_{2 s}-t\left(M_{2}-M_{1}\right) Y=r_{0}+t M_{1} Y
$$

This (and $g_{c}=g_{s}$ ) implies

$$
U\left(M_{1}-b_{1 c}-g_{c}+T, g_{c}\right)<U\left(M_{1}-t M_{1} Y-r_{0}-g_{s}+T, g_{s}\right)
$$


The right-hand side is the utility achieved by a poor household moving to the suburban fringe. Therefore the inequality implies that a poor household can achieve more utility by moving, which is inconsistent with equilibrium.

Case (c.2): poor and rich households live in both jurisdictions. The boundary between rich and poor households in the city has radius $x$ and in the suburb has radius $y$. Rent continuity at $x$ and $y$ (and $\left.b_{2 c}=b_{2 s}\right)$ implies:

$$
b_{1 c}=b_{2 c}-t\left(M_{2}-M_{1}\right) x=b_{2 s}-t\left(M_{2}-M_{1}\right) x=b_{1 s}+t\left(M_{2}-M_{1}\right)(y-x)>b_{1 s} .
$$

This $\left(\right.$ and $\left.g_{c}=g_{s}\right)$ implies

$$
U\left(M_{1}-b_{1 c}-g_{c}+T, g_{c}\right)<U\left(M_{1}-b_{1 s}-g_{s}+T, g_{s}\right)
$$

which contradicts the assumption that poor households live in both jurisdictions. 


\section{ENDNOTES}

1. Ross and Yinger [22] review this literature.

2. If the income elasticities of land demand and of commuting costs are equal, the relationship between household income and distance from the metropolitan center is indeterminate. This is the case considered theoretically by Montesano [16] and considered statistically relevant by Wheaton [26]).

3. Table 3, 1990 Census of Population, Social and Economic Characteristics. Washington, D.C.: U.S. Department of Commerce.

4. The assumption of exogenous land demand is not critical for the existence of equilibria with income mixing. In particular, simulations confirm the existence of an equilibrium with income mixing if land demand is price-sensitive and income-sensitive (de Bartolome and Ross [6]).

5. This sorting result is a consequence of assuming that the income elasticity of land demand is zero and that per mile commuting costs increase with income. As noted in the Introduction, in general the pattern of sorting within a jurisdiction is determined by comparing the income elasticity of land demand with the income elasticity of per mile transportation costs (Wheaton [26]).

6. Many cities have business districts dispersed throughout the metropolitan area in addition to the central business district. Our model of a circular metropolitan area and a central business district is therefore stylized. It is constructed to show that income mixing can occur. The logic can be extended to more complex spatial patterns.

7. The assumptions of a fixed lot size and myopia ensure that household preferences are singlepeaked and that all households of the same income in a jurisdiction desire the same public service level. In addition, the fixed lot size assumption eliminates the possibility of an infinite regress in the adjustment process between the housing market and the myopic voting equilibria (see Epple, Filimon and Romer [9],[10]).

8. For ease of presentation, we assume that roads and public facilities consume no land. If roads and public facilities consume a fraction $\alpha$ of the developed area, the equations are:

$(1-\alpha) \pi x^{2}=(1-\theta) N a$ and $(1-\alpha) \pi Y^{2}=N a$.

9. The exact form of this assumption depends on the case being considered. For example, if rich households do not fill the city, a sufficient condition is that a poor household could afford to live at the limit of suburban development if all poor households were to live in the suburb:

$M_{1}>t M_{1} \hat{Y}+a r_{0}$ where $\pi\left(\hat{Y}^{2}-B^{2}\right)=\theta N a$. This is unduly restrictive because some poor households may live in the city, so that the limit of suburban development is less than $\hat{Y}$, and $T>0$.

10. In addition, we require $0<x<B<Y$ and all households must have positive consumption. In fact, Inequality (6) does not bind in this case or in the subsequent cases when $X<B$ : Selfselection requires:

$$
\underset{g}{\max } U\left(M_{2}-b_{2 c}-g+T, g\right) \geq U\left(M_{2}-t M_{2} B-\left(b_{1 s}-t M_{1} B\right)-g_{s}+T, g_{s}\right)
$$


A sufficient condition is: $b_{2 c} \leq b_{1 s}+t\left(M_{2}-M_{1}\right) B$.

If $x<X$ :

Equation (4) implies: $b_{2 c}=b_{1 c}+t\left(M_{2}-M_{1}\right) x$.

Equation (5) and (8) imply: $b_{1 c} \leq b_{1 s}$.

Hence $x<B$ implies: $\quad b_{2 c}=b_{1 c}+t\left(M_{2}-M_{1}\right) x \leq b_{1 s}+t\left(M_{2}-M_{1}\right) B$.

If $x=X$ : there is undeveloped city land and hence at the edge of development $b_{2 c}-t M_{2} x=r_{0}$. Using with Equation (2) implies: $b_{2 c}=b_{1 s}+t\left(M_{2} x-M_{1} Y\right)<b_{1 s}+t\left(M_{2} B-M_{1} B\right)$.

11. The rent-schedules are piecewise linear because of the assumption that a household's demand for land is exogenous.

12. The proofs are available from the authors on request.

13. Sufficient conditions for the existence of an equilibrium with income mixing are available from the authors upon request.

14. The problem of negative consumption at high $\alpha$ does not occur in Figure 4 because poor households, by moving to the suburb, can "escape" the high public services voted by the rich.

15. We are currently researching whether the results are robust if the large single suburb is replaced by many small suburbs.

16. Provided rich households' willingness to pay for a higher public service is sufficiently strong, which is true for the range of parameter values considered by de Bartolome and Ross [6].

17. The maintained assumption that poor households form the majority in the city implies $\pi \mathrm{x}^{2} \leq$ $1 / 2 \pi \mathrm{B}^{2}$ and the maintained assumption that rich households form the majority in the suburb implies $\pi\left(\mathrm{y}^{2}-\mathrm{B}^{2}\right) \geq 1 / 2 \pi\left(\mathrm{Y}^{2}-\mathrm{B}^{2}\right)$.

18. If $x=X, b_{1 c}$ is the rent plus commuting cost a poor household would pay if it were to move to the city 